\title{
Clonal evolution of lymphoblastoid cell lines
}

\author{
Julie L Ryan ${ }^{1}$, William K Kaufmann ${ }^{2,3}$, Nancy Raab-Traub ${ }^{3,4}$, Stephen E Oglesbee ${ }^{3,5}$, \\ Lisa A Carey ${ }^{3,5}$ and Margaret L Gulley ${ }^{2,3}$ \\ ${ }^{1}$ Departments of Dermatology and Radiation Oncology, University of Rochester James P. Wilmot Cancer \\ Center, Rochester, NY, USA; ${ }^{2}$ Department of Pathology and Laboratory Medicine, University of North \\ Carolina at Chapel Hill, Chapel Hill, NC, USA; ${ }^{3}$ Lineberger Comprehensive Cancer Center, University of \\ North Carolina at Chapel Hill, Chapel Hill, NC, USA; ${ }^{4}$ Department of Microbiology and Immunology, \\ University of North Carolina at Chapel Hill, Chapel Hill, NC, USA and ${ }^{5}$ Department of Medicine, \\ University of North Carolina at Chapel Hill, Chapel Hill, NC, USA
}

\begin{abstract}
Lymphoblastoid cell lines represent Epstein-Barr virus (EBV)-immortalized B lymphocytes, which are typically prepared by in vitro culture of normal blood cells. In this study, we evaluated the kinetics of clonal evolution in lymphoblastoid cell lines (LCLs) established from five different donors. Immunoglobulin heavy chain (IGH) and T-cell receptor gamma (TRG) gene rearrangements were tracked over time using PCR, while EBV clonality was tracked using Southern blot analysis of the viral terminal repeat fragment. All five cultures evolved towards monoclonal B cells within 8 weeks, while T lymphocytes disappeared over the same period. No significant association was found between the rapidity of clonal emergence and either the proliferation rate or the size of the EBV terminal repeat fragment, suggesting the random nature of clonal selection. Our results suggest that EBV-driven B lymphocytes rapidly progress from polyclonal to virtually monoclonal, which has implications for the pace at which lymphoma might evolve in vivo. In addition, our findings indicate that established lymphobastoid cell lines are not an ideal 'normal control' for human B lymphocytes because they do not represent the spectrum of polyclonal $B$ cells found in healthy humans; instead, they primarily represent the progeny of a single B lymphocyte.
\end{abstract}

Laboratory Investigation (2006) 86, 1193-1200. doi:10.1038/labinvest.3700472; published online 2 October 2006

Keywords: Epstein-Barr virus; lymphoblastoid cell lines; clonal evolution; B lymphocyte; IGH gene

Nearly every human being is infected by EpsteinBarr virus (EBV) before adulthood, and the virus can drive proliferation of B lymphocytes in vivo and in vitro. The human immune system is responsible for controlling this proliferation so that virally infected lymphocytes are not permitted to outgrow normal lymphocytes. In immunocompromised transplant recipients, however, EBV-driven lymphoproliferations can become unregulated and can proceed to kill the patient if not recognized and treated. Interestingly, these post-transplant lymphoproliferations are monoclonal, suggesting that a single infected cell outgrew its infected and uninfected partners. These lymphoproliferations are recognized

Correspondence: Dr ML Gulley, MD, Department of Pathology and Laboratory Medicine, University of North Carolina, 101 Manning Dr, 913 Brinkhous-Bullitt Building, Chapel Hill, NC 27599-7525, USA.

E-mail: margaret_gulley@med.unc.edu

Received 7 February 2006; revised 1 August 2006; accepted 3 August 2006; published online 2 October 2006 as early as 3 weeks after transplantation, suggesting that evolution to monoclonality can occur quickly.

Lymphoblastoid cell lines (LCLs) are produced by growing EBV-infected B lymphocytes in vitro. These cell lines are widely used in research laboratories because they provide an unlimited supply of $\mathrm{B}$ lymphocytes from any human being. Lymphoblastoid cell lines are created by taking blood cells and culturing them in enriched media until the only cells surviving are the naturally EBV-infected B lymphocytes. Alternatively, one can take uninfected blood cells and co-culture them with EBV virions, resulting in infection and outgrowth of the EBV-positive B lymphocytes. Researchers commonly assume that the B lymphocytes that are immortalized in this way are representative of normal cells from the donor, and in many respects the immortalized cells reproduce phenotypes that are found in their uninfected parental counterparts. ${ }^{1}$ However, lymphoblastoid cell lines are monoclonal unlike their polyclonal physiologic counterparts. This study investigates the kinetics by which 
lymphocytes progress from polyclonality towards monoclonality.

Clonality testing relies in part on the fact that lymphocytes physiologically rearrange their DNA. This rearrangement of the immunoglobulin or T-cell receptor genes in $\mathrm{B}$ cells and $\mathrm{T}$ cells, respectively, allows these cells to express unique proteins that can recognize foreign antigens. A healthy immune system contains polyclonal lymphocytes, each of which arose from a precursor cell that underwent a unique gene rearrangement. When one of these cells acquires a genetic defect resulting in malignant transformation, then the resulting clone of neoplastic lymphocytes contains the same unique gene rearrangement as the original cell. The fact that lymphoid neoplasms are monoclonal whereas normal lymphocytes are polyclonal can be used as a diagnostic tool to help identify lymphoid neoplasia.

Clonality is readily measured by evaluating the structure of the rearranged immunoglobulin heavy chain (IGH) gene or the T-cell receptor gamma $(T R G)$ gene. These two genes are rearranged very early during B or T cell ontogeny, and they are commonly targeted in clinical assays that distinguish monoclonal from polyclonal lymphoproliferations. Polymerase chain reaction (PCR) amplifies the rearranged gene using consensus primers targeting variable and joining region segments. Monoclonal populations exhibit a single-sized product, whereas polyclonal populations contain a variety of product sizes depending on which of the many variable and joining segments (and, in the case of IGH, diversity segments, as well) was spliced into the rearranged gene. A mixture of monoclonal and polyclonal cells would exhibit a dominant product among a background of variably sized products.

EBV-infected lymphocytes harbor a second marker of clonality in their viral genome structure. The EBV genome contains variable numbers of tandemly repeated sequences, and the number of these repeats usually differs among infected cells or clones of cells. Southern blot analysis can be used to determine the clonality of EBV-infected tissues with respect to the structure of the viral terminal repeat sequences. This assay was first described by Raab-Traub and Flynn in $1986,{ }^{2}$ and it relies on the assumption that a given cell is apparently infected only once. Each infecting EBV genome contains a certain number (up to 20) terminal repeat sequences. During cell division, viral DNA is replicated alongside human chromosomes, so the relatively unique viral terminal repeat number that is present in a given cell is inherited by its cellular progeny. Analysis of clinical samples has shown that most EBV-associated tumors as well as lymphoblastoid cell lines harbor monoclonal EBV DNA, ${ }^{2-5}$ although a small subset of immunocompromised patients have either oligoclonal or polyclonal lymphoid proliferations. ${ }^{6,7}$ The time course by which EBV drives monoclonal outgrowth has not be characterized.
In the current study, we evaluated the in vitro kinetics of clonal evolution in cultured blood lymphocytes taken from five individuals. B-cell clonality was measured by PCR amplification of the rearranged $I G H$ gene, while T-cell clonality was measured by analogous PCR of the TRG gene. EBV clonality was measured by Southern blot analysis of the viral terminal repeat segments. Analysis of results at multiple timepoints over a 2-month period demonstrates rapid decline of $\mathrm{T}$ cells in concert with rapid evolution from polyclonal to monoclonal $\mathrm{B}$ cells. The findings have implications for clinical as well as research studies on EBV-infected lymphocytes.

\section{Materials and methods}

\section{Patient Samples}

Blood was collected from five individuals who had no signs of lymphoid neoplasia (LCL 1-5). Four of these individuals were newly diagnosed breast cancer patients (LCL-1, -2, -3, -4) who had not yet received any treatment for their cancer. The fifth was a cancer-free patient in an outpatient clinic at UNC Hospitals (LCL-5). Peripheral blood lymphocytes (PBLs) were separated using Ficoll centrifugation of $25 \mathrm{ml}$ of blood anticoagulated with EDTA. The PBLs were incubated overnight with $3 \mathrm{ml}$ of supernatant containing EBV B95.8 strain infectious particles in a T-25 flask at $37^{\circ} \mathrm{C}$ in $5 \% \mathrm{CO}_{2}$ incubator. The following day, $7 \mathrm{ml}$ of RPMI media containing $15 \%$ fetal bovine serum (FBS) and $50 \mu \mathrm{g} / \mathrm{ml}$ of cyclosporin were added to the flask. Approximately 2 to 3 weeks later, when cell numbers had expanded to $3 \times 10^{7}$, samples of $10^{6}$ cells were cryopreserved at $-140^{\circ} \mathrm{C}$. Subsequent experiments were initiated by reconstituting cultures of the five cell lines by inoculating $10 \mathrm{ml}$ of RPMI containing $15 \%$ FBS with $10^{6}$ thawed cells. The first collection of cells at 'time 0 ' was made less than a week later when cell concentration reached $1-2 \times 10^{6} \mathrm{cells} / \mathrm{ml}$. Then at weekly intervals the cells were diluted to $3 \times 10^{5}$ per $\mathrm{ml}$ in fresh growth medium. An additional $10^{6}$ cells were collected at 1, 2, 4, and 8 weeks after the initial 'time 0' cell collection. Cells pellets were stored at $-80^{\circ} \mathrm{C}$ until DNA extraction.

\section{Proliferative Index}

Proliferative index was established by flow cytometry to determine the number of cells in the $S$ phase of the cell cycle. This measurement was done between 'time 0 ' and week 1 after reconstitution of cultures. Cells were seeded at $3 \times 10^{5} / \mathrm{ml}$ in fresh growth medium and incubated for $48 \mathrm{~h}$. Then $3 \times 10^{5}$ cells were sedimented and washed in phosphatebuffered saline, then fixed in $70 \%$ ethanol. Fixed cells were mixed with $10 \mu \mathrm{g} / \mathrm{mlRNase}$ and $25 \mu \mathrm{g} / \mathrm{ml}$ propidium iodide and then analyzed for DNA 
content using a FACscan (Becton Dickenson) flow cytometer. Histograms of DNA content for 30000 cells were analyzed by the ModFit commercial software to determine the percentages of cells in G0/G1 (2N DNA content), S ( $>2 \mathrm{~N}$ DNA content $<4 \mathrm{~N}$ ) and G2/M (4N DNA content). Each analysis of DNA content was performed on three consecutive days and mean values were determined.

\section{DNA Extraction}

DNA was extracted from each cell sample using the Purgene Cell and Tissue DNA Isolation kit (Gentra Systems, Minneapolis, MN, USA) using the manufacturer's 'DNA purification from 1 to 2 million cultured cells' protocol. An alteration was made in the 'standard DNA hydration' step in which $100 \mu \mathrm{l}$ DNA Hydration Solution, instead of $50 \mu \mathrm{l}$, was used to rehydrate the DNA pellet at $65^{\circ} \mathrm{C}$ for $1.5 \mathrm{~h}$. The purified DNA was stored at $-20^{\circ} \mathrm{C}$ until analysis.

\section{Immunoglobulin Heavy Chain Gene Rearrangement}

PCR amplification of IGH V-D-J junctions was performed using published primers targeting framework $3 \mathrm{VH}$ region (FRIII) and the JH consensus sequences (JHa). ${ }^{8}$ The JHa primer was labeled with 6FAM fluorochrome on its $5^{\prime}$ terminus so that the product could be detected by capillary gel electrophoresis on an ABI 310 instrument (Applied Biosystems). Namalwa Burkitt lymphoma cell line DNA served as the positive control for monoclonal IGH gene rearrangement, while DNA from the buffy coat layer of whole blood from healthy donors served as the polyclonal control. To monitor for amplicon contamination, a 'no template control' representing deionized water was substituted for template DNA in each run. The $50 \mu \mathrm{l}$ reaction consisted of: $1 \times$ PCR buffer without $\mathrm{MgCl}_{2}$ and $2 \mu \mathrm{l} 50 \mathrm{mM} \mathrm{MgCl}$ (Invitrogen, Alameda, CA, USA), $4 \mu \mathrm{l}$ Gene Amp $10 \mathrm{mM}$ dNTPs with dTTP (Applied Biosystems, Branchburg, NJ, USA), 50 pmol of each primer, $0.85 \mathrm{U}$ of AmpliTaq Gold DNA polymerase (Applied Biosystems), $1 \mu \mathrm{l}$ of DNA template, and nuclease-free water (Promega, Madison, WI, USA). A replicate sample was run in parallel except that the replicate contained $1 \mu \mathrm{l}$ of a 1:10 dilution of DNA template. The reaction conditions were: $95^{\circ} \mathrm{C}$ for $10 \mathrm{~min}$; 45 cycles of $95^{\circ} \mathrm{C}$ for $45 \mathrm{~s}, 55^{\circ} \mathrm{C}$ for $1 \mathrm{~min}$, and $75^{\circ} \mathrm{C}$ for $1 \mathrm{~min}$; $72^{\circ} \mathrm{C}$ for $7 \mathrm{~min}$.

Both agarose gel electrophoresis and capillary gel electrophoresis were used to analyze the PCR products. The former was a 3.5\% 2.5:1 NuSieve: BioRad agarose gel with $0.05 \%$ ethidium bromide run in $0.5 \times$ TBE. Samples containing polyclonal B cells exhibited a smear of bands between 100$120 \mathrm{bp}$, whereas samples containing monoclonal $B$ cells exhibited one or two crisp bands in the
100-120 bp region (representing mono- or biallelic rearrangement). Samples exhibiting three or more crisp bands in the 100-120 bp region were considered to be oligoclonal.

\section{T-Cell Receptor Gamma Gene Rearrangement}

PCR amplification of the TRG gene rearrangement was performed using a cocktail of eight primers (five $\mathrm{V} \gamma$ region primers and three $\mathrm{J} \gamma$ region primers) as described by Greiner and Rubocki. ${ }^{9}$ All of the $\mathrm{J} \gamma$ region primers were labeled with $6 \mathrm{FAM}$ fluorochrome on their $5^{\prime}$ terminus. The $50 \mu \mathrm{l}$ reaction consisted of: $1 \times$ PCR Buffer with $15 \mathrm{mM} \mathrm{MgCl}_{2}$ (Applied Biosystems), $2 \mu \mathrm{l}$ of Gene Amp10mM dNTPs with dTTP (Applied Biosystems), $10 \mathrm{pmol}$ of each primer $(\mathrm{V} \gamma 2, \mathrm{~V} \gamma 3, \mathrm{~V} \gamma 9, \mathrm{~V} \gamma 10, \mathrm{~V} \gamma 11, \mathrm{~J} \gamma 1 / \mathrm{J} \gamma 2$, $\mathrm{J} \gamma \mathrm{P}, \mathrm{J} \gamma \mathrm{P} 1 / \mathrm{J} \gamma \mathrm{P} 2), 1.25 \mathrm{U}$ AmpliTaq Gold DNA polymerase, deionized water, and $1 \mu \mathrm{l}$ of DNA template or, in the replicate sample, a 1:10 dilution of template. Jurkat T-cell lymphoma line DNA was used as the positive control for monoclonal T cells, while reactive tonsil DNA was used as the control for polyclonal T cells, and a 'no template control' was included in each run. PCR products $(15 \mu \mathrm{l})$ were electrophoresed on a $10 \%$ polyacrylamide gel in $1 \times$ TBE and stained with ethidium bromide. Products were also analyzed by capillary gel electrophoresis.

\section{Capillary Gel Electrophoresis}

Capillary gel electrophoresis was performed on an ABI 310 Genetic Analyzer using ABI Prism Gene Scan ${ }^{\mathbb{R}} 3.1$ software. A reaction mix was made containing $24 \mu \mathrm{l}$ formamide, $0.5 \mu \mathrm{l}$ ROX-labeled sizing standard, and $1 \mu \mathrm{l}$ of PCR product. The IGH gene products were diluted 1:50 with deionized water before adding to the reaction mix. The samples were denatured at $95^{\circ} \mathrm{C}$ for $3 \mathrm{~min}$, iced for $3 \mathrm{~min}$, and loaded on the instrument with an injection time of $1 \mathrm{~s}$. In the resulting electropherogram, IGH gene rearrangements were represented by peaks in the 70-130 bp region, with a separation of $3 \mathrm{bp}$ between each peak. TRG gene rearrangements had peaks between 160 and $220 \mathrm{bp}$. The height of the peaks reflected the prominence of various clones of $\mathrm{B}$ or $\mathrm{T}$ cells in the each sample.

\section{EBV Clonality Assay by Southern Blot}

To perform the EBV clonality assay, $5 \mu \mathrm{g}$ of extracted DNA was first digested using BamH1 restriction enzyme to cut sequences flanking the region containing the terminal repeat sequences. Following electrophoresis and transfer, a labeled internal probe (Xho1.9 probe targeting the right end of the EBV genome) was applied to detect fragments containing the terminal repeats. ${ }^{10}$ Analysis of the band pattern 
distinguishes monoclonal from oligoclonal, polyclonal, or uninfected samples. The positive controls were three different levels of the EBV-infected Raji Burkitt lymphoma cell line DNA corresponding to EBV genomic copy numbers of 50, 5, and 1 copy. Raji DNA produces a single band of approximately $23 \mathrm{~kb}$, confirming that monoclonal EBV is present. Monoclonal or oligoclonal EBV is represented by a single or several bands in the $6-23 \mathrm{~kb}$ range, while polyclonal populations have many different bands in this range.

\section{Results}

\section{Evolution of Monoclonal B Cells}

The results for $I G H$ gene rearrangement for all of the lymphoblastoid cell lines revealed the emergence of
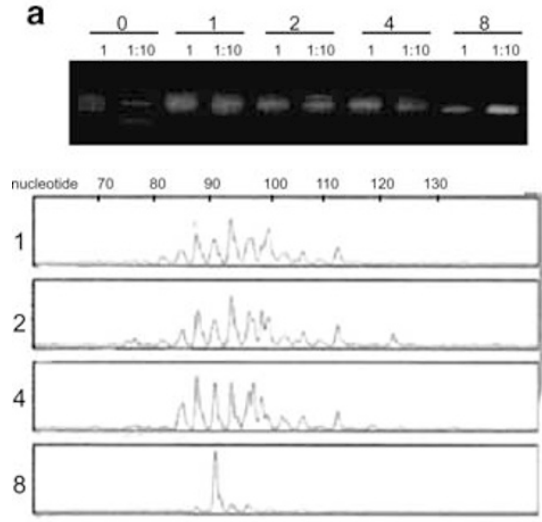

C $\quad \frac{0}{1: 1: 10} \frac{1}{1: 1: 10} \frac{2}{1: 1: 10} \frac{4}{1: 1: 10} \frac{8}{1: 1: 10}$

$-\sec 0--=$
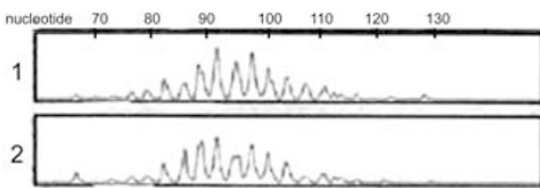

4

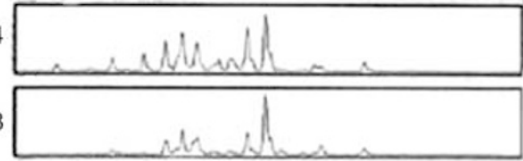

b $\frac{0}{1: 1: 10} \frac{1}{1: 1: 10} \frac{2}{1,1: 10} \frac{4}{1 \quad 1: 10} \frac{8}{1: 1: 0}$
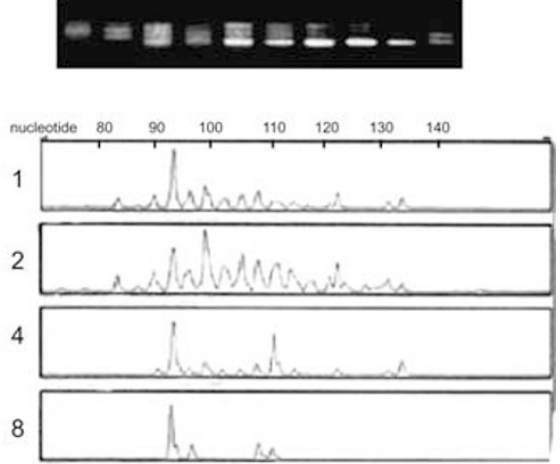

d
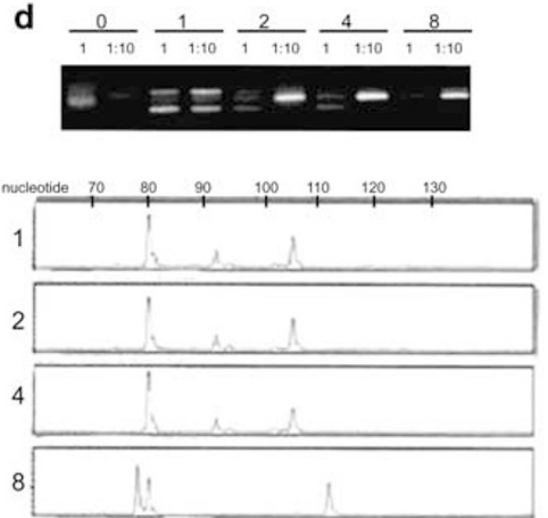

e $\frac{0}{1: 10} \frac{1}{1: 1: 10} \frac{2}{1: 1: 10} \frac{4}{1: 1: 10} \frac{8}{1: 1: 10}$
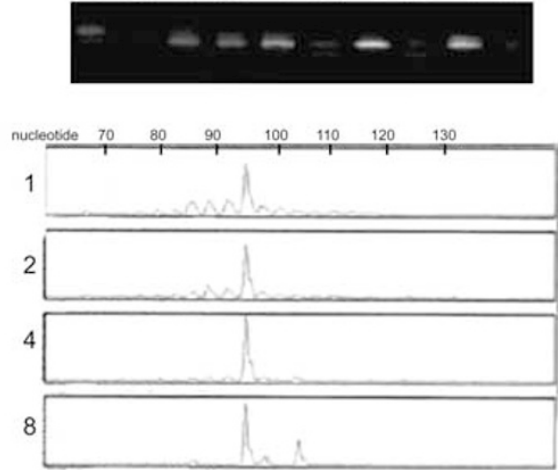

Figure 1 B-lymphocytes evolve towards monoclonality within 8 weeks. The upper panel shows replicate band patterns for IGH gene rearrangement on agarose gels while the lower panel shows corresponding capillary gel electropherograms of the same amplification products at weeks 1-8. (a-e) Panels a-e correspond to LCL-1-LCL-5. A smear of bands on the agarose gels corresponds to a bell-shaped curve of peak sizes on the capillary gels, while a dominant crisp band in agarose is seen as a major peak in capillary gels. In each of the five samples, a single clone predominates by 8 weeks of culture. In the agarose gel of LCL 4, the consistent duo of bands in weeks 1-4 is interpreted to represent biclonal B cells, as opposed to biallelic IGH rearrangement in a monoclonal line, as evidenced by the single band at week 8 ; the aberrant pattern at week 8 in the capillary gel does not match the clear monoclonal pattern seen in the corresponding agarose gel of the same product. 
a monoclonal lymphocyte population (Figure 1). All five cell populations were virtually monoclonal by week 8, however, the time of emergence varied for each individual.

The LCL-1, LCL-2, and LCL-3 lines retained a substantial number of polyclonal B lymphocytes through week 2 , although few, if any, were visible by week 8. In contrast, LCL-4 and LCL-5 had a dominant clone by week 1 that remained dominant through week 8. Although the LCL-2, LCL-3, LCL-4 were not completely monoclonal by week 8 , a dominant clone could be easily distinguished from other persisting clones. We cannot exclude that minor clones persist long-term.

The peaks ranged between the expected product size of $70-130 \mathrm{bp}$ for all samples. The size of the most prominent product often varied across time in a given specimen, implying that different gene rearrangements were present in varying abundance and that some clones died off while others thrived. One line eventually outgrew the others and dominated the culture. The varying size of the dominant clone among the five different samples confirms the apparently random nature of clonal selection and the absence of amplicon contamination.

The time zero results (shown by agarose gel in Figure 1) do not appear to be reproducible. This finding is most likely explained by the small number of cells available for testing at time 0 , resulting in sampling error whereby only a few cells were evaluated in each replicate. This sampling error results in the appearance of a restricted band pattern that is not the same in the neat (1) and 1:10 template dilutions.

\section{Progressive Loss of T Cells}

During the in vitro infection procedure, the cells were treated with $50 \mu \mathrm{g} / \mathrm{ml}$ of cyclosporin to inhibit cytotoxic T-cell immune response against viral antigens and promote emergence of infected B lymphocytes. Thus, we expected the $\mathrm{T}$ cells in the primary culture to be ineffective and to eventually die off, which is what was observed. The time course of this process, as monitored by $T R G$ gene rearrangement amplification, is depicted in Figure 2.

No significant TRG rearrangements remained in the cultured samples by week 8 . In all five of the cultures, there appeared to be certain $\mathrm{T}$ cell clones that persisted longer than others, with a progression from polyclonal to oligoclonal to total absence of $\mathrm{T}$ cells over time.

\section{EBV Clonality}

EBV clonality was measured by Southern blot analysis of the viral terminal repeat fragment. Although all samples were immortalized in the same manner and with the same strain of EBV, analysis of EBV genomic structure showed that
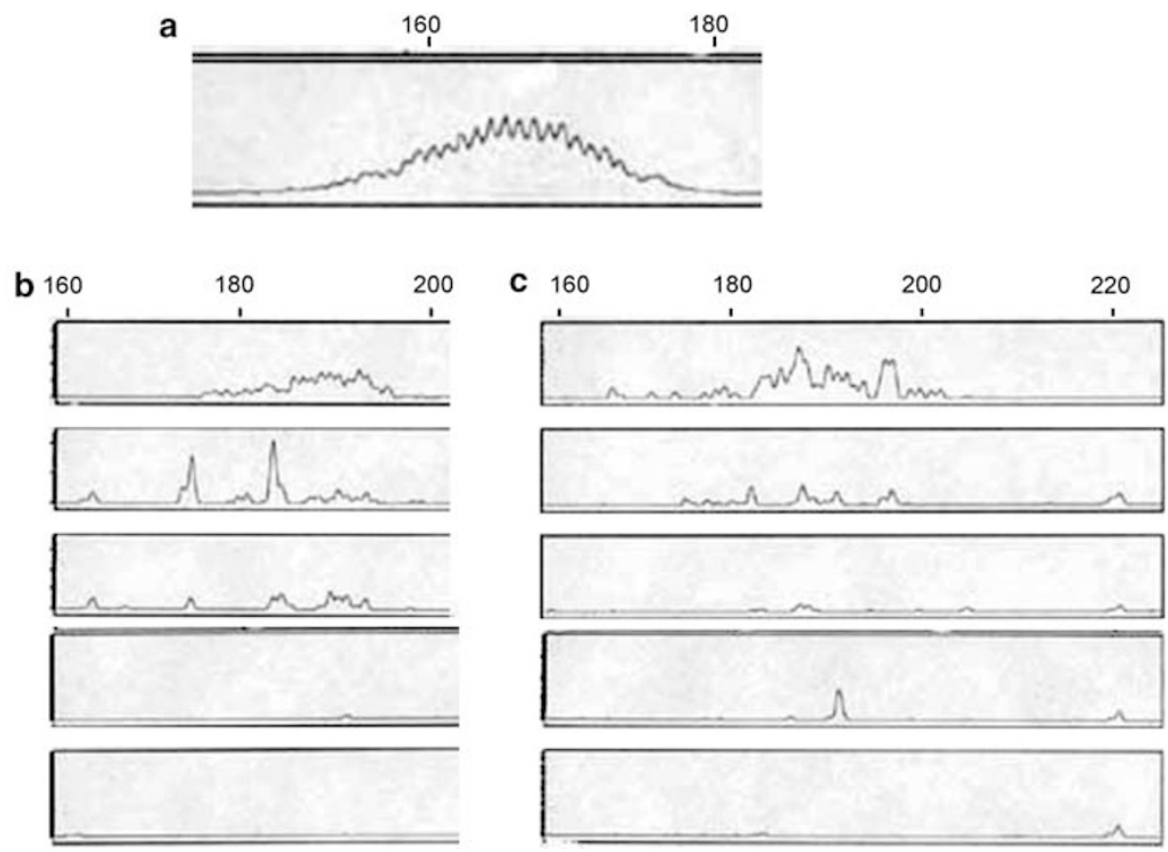

Figure 2 T lymphocytes are eliminated from culture within 8 weeks. Capillary electropherograms of the products of TRG amplification reveal that: (a) polyclonal T cells are found in a reactive tonsil control sample. (b) LCL-5 has polyclonal T cells at time 0, two dominant clonal peaks at week 1 , few oligoclonal T cells at week 2 , and no significant T cells by week 4. (c) LCL-4 retains oligoclonal T cells through week 4 , with no significant T cells by week 8 . 


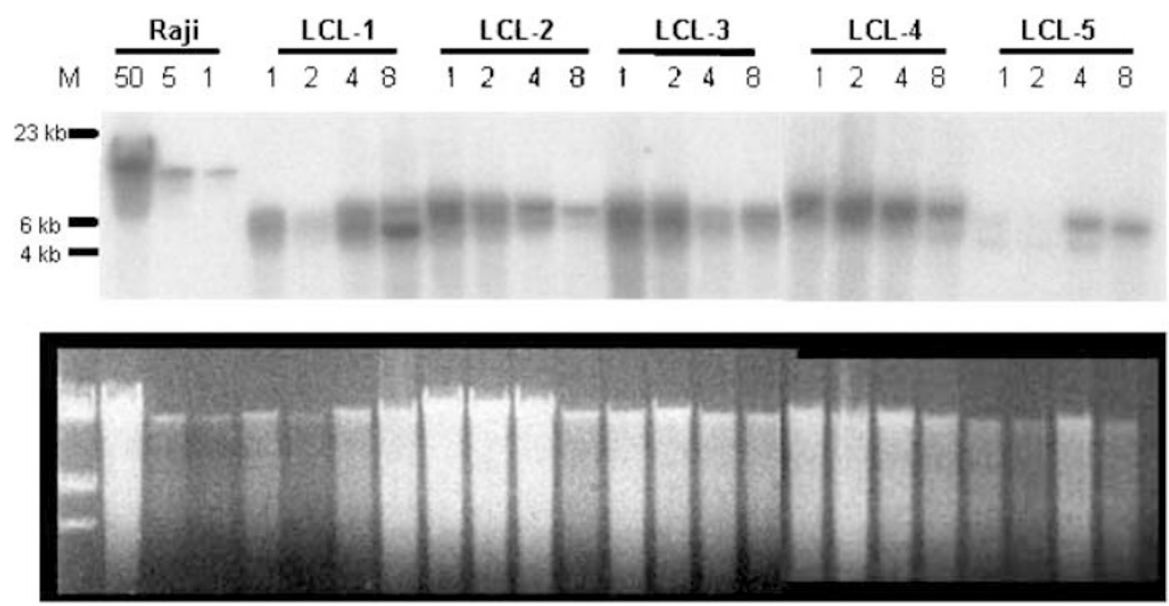

Figure 3 EBV DNA becomes clonal within 8 weeks in cultured lymphocytes. Southern blot analysis of EBV DNA was performed using a probe for the terminal repeat fragment. The upper panel shows the blot and the lower panel shows the corresponding gel stained with ethidium bromide. The Raji cell line controls depict monoclonality at levels of 50 copies, five copies, and one copy of EBV DNA per cell. The subsequent sets of four lanes each represent the five LCL samples at weeks 1, 2, 4, and 8. In each LCL, there is progression to a more restricted band pattern over time.

Table 1 Proliferative index compared to interpretations of B Cell and EBV clonality

\begin{tabular}{|c|c|c|c|c|c|c|c|c|c|}
\hline \multirow{2}{*}{$\begin{array}{l}\text { Sample } \\
\text { Week }\end{array}$} & \multirow[t]{2}{*}{ Proliferative index } & \multicolumn{4}{|c|}{ IGH gene rearrangement } & \multicolumn{4}{|c|}{ EBV clonality } \\
\hline & & 1 & 2 & 4 & 8 & 1 & 2 & 4 & 8 \\
\hline LCL-1 & $41 \%$ & $\mathrm{p}$ & $\mathrm{p}$ & $\mathrm{p}$ & $\mathrm{m}$ & $\mathrm{p}$ & $\mathrm{p}$ & o & $\mathrm{b}$ \\
\hline LCL-2 & $36 \%$ & $\mathrm{p}$ & $\mathrm{P}$ & o & $\mathrm{b}$ & $\mathrm{p}$ & $\mathrm{b}$ & $\mathrm{b}$ & $\mathrm{b}$ \\
\hline LCL-3 & $41 \%$ & $\mathrm{p}$ & $\mathrm{p}$ & $\mathrm{p}$ & $\mathrm{b}$ & $\mathrm{p}$ & $\mathrm{p}$ & $\mathrm{b}$ & $\mathrm{b}$ \\
\hline LCL-4 & $38 \%$ & o & o & o & $\mathrm{b}$ & b & $\mathrm{b}$ & $\mathrm{b}$ & $\mathrm{m}$ \\
\hline LCL-5 & $28 \%$ & o & $\mathrm{o}$ & $\mathrm{m}$ & $\mathrm{m}$ & $\mathrm{p}$ & $\mathrm{p}$ & $\mathrm{p}$ & $\mathrm{b}$ \\
\hline
\end{tabular}

Abbreviations: $\mathrm{p}=$ polyclonal; $\mathrm{o}=$ oligoclonal; $\mathrm{b}=$ biclonal; $\mathrm{m}=$ monoclonal.

different virion structures emerged in the dominant clones of each culture (see Figure 3). The time course of clonal evolution was similar in all five cultures, with distinct clones predominating by week 4 and progressing to biclonal or monoclonal populations by week 8 .

\section{Proliferative Index}

Flow cytometry was used to measure the proliferative index, which is the proportion of cells in $\mathrm{S}$ phase of the cell cycle after $48 \mathrm{~h}$ in culture. Cultures were sampled between 'time 0' and week 1 when oligoclonality was already emerging. The results of the proliferative index are shown in association with the progression of clonality in Table 1. There was little difference in proliferative indices across the samples (28-41\%), and no major trends in clonal emergence were seen in relation to proliferation rate. Table 1 also shows that the emergence of a dominant IGH clone does not necessarily coincide chronologically with the emergence of a dominant EBV clone.

\section{Discussion}

EBV is known to drive proliferation of B cells in vivo and in vitro. In this study, we showed that one B cell clone quickly emerged from among all of the B cells that were infected in vitro, suggesting that a single clone had a substantial growth advantage over its cohorts. Analysis of the time course showed that T cell loss proceeded in concert with B cell expansion and that certain $\mathrm{T}$ cell clones died off more slowly than others, just as certain B cell clones emerged and then were dominated by a single B cell clone.

Cyclosporin is one of the immunosuppressive agents used to prevent graft rejection in transplant recipients. We used cyclosporin in our cultures to inhibit $\mathrm{T}$ cell immunity; thus, our culture model may have some features in common with the clinical situation in immunosuppressed patients. In fact, it is known that most EBV-driven post-transplant lymphoproliferations are monoclonal, with only rare instances of biclonal or polyclonal neoplasms reported..$^{4,6,7}$ The time course of clonal evolution in our cell cultures implies that monoclonality can emerge within weeks of $\mathrm{T}$ cell depletion, and the 
very earliest clinical examples of post-transplant lymphoproliferations are diagnosed in a matter of a few weeks after transplantation.

Interestingly, the time course of IGH clonal emergence did not coincide well with the time course of EBV clonal emergence. In fact, the IGH assay indicated monoclonality by 8 weeks, whereas the EBV assay showed mainly biclonal populations at 8 weeks. We note that the IGH assay detects only about $80 \%$ of all B-cell clones; it fails to amplify certain $I G H$ rearrangements, mainly because somatic mutation interferes with primer binding. Therefore, we may be missing some B-cell clones with the IGH assay. Uninfected B cells may die off before infected $\mathrm{B}$ cells, and these uninfected cells are not even represented in the EBV clonality assay, although they are almost certainly represented in early time points of the IGH assay. These factors could explain, at least in part, the observed differences in clonal evolution rate as assessed by the two assays.

It is possible that early cryopreservation contributed to focal cell death and thus to the emergence of dominant clones in our culture system. However, the rapid in vivo emergence of a dominant clone in transplant recipients with an EBV-driven lymphoproliferation suggests that our in vitro observations reflect a similar clonal evolution that occurs during human tumorigenesis.

The mechanism that allows one infected cell to outgrow its infected cohorts is not known. Interestingly, the outgrowth of infected clones is not restricted to $\mathrm{B}$ lymphocytes. A previous study of lung carcinoma cells (the CCL-185 line) infected with EBV showed progression to EBV monoclonality after 2 months in culture. ${ }^{11}$ It is possible that somatic mutation of the human genome in a single cell could impart a growth advantage by, for example, activating an oncogene or inactivating a tumor suppressor gene. Alternatively, somatic mutation in the viral genome could make that virion more oncogenic. Another theory is that the number of terminal repeats could affect expression or structure of the viral LMP2 gene, which is encoded across these repeat sequences. Likewise, the terminal repeat number could affect expression of the nearby viral $L M P 1$ gene that is known to have growthpromoting properties. In this regard, it should be noted that all five of our 8-week old LCL lines appear to have different EBV terminal repeat sizes, and it does not appear that there was a selection bias towards small or large repeat numbers. A final theory is that the particular antibody encoded in one of the infected cells allowed that B lymphocyte to grow faster in its particular culture environment. In other words, it may have been stimulated by an antigen in the culture to divide and produce memory B cells, as would be its normal function in vivo. As there are billions of possible antigen receptor structures and thousands of target antigens in the culture vial, one would not expect to find the exact same immunoglobulin heavy or light chain gene rearrangement in one lymphoblastoid cell line compared to another.

Regardless of the mechanism for clonal outgrowth, our findings suggest that there is clonal progression within months of lymphocyte cell culture. This observation implies that a lymphoblastoid cell line does not represent normal polyclonal lymphocytes but rather that it is dominated by a single clone of fast-growing B lymphocytes. This result has implications for researchers who seek a 'normal control' in their experiments. Although lymphoblastoid cell lines are often derived from normal lymphocytes of a healthy individual, they are not as representative of normal cells as are fresh lymphocytes taken from a healthy donor.

\section{Acknowledgements}

This work was supported in part by an Environmental Pathology Training Grant (T32-ES07017), and PHS Grants CA81343, P30-CA16086, CA16086 and P30-ES10126. The authors thank Rachel Edwards, Hongxin Fan, Jeff Sailus, Marc Lotano, and Lynda Sawyer for technical assistance and advice, and the staff of the Lineberger Comprehensive Cancer Center Tissue Culture Facility for generating the lymphoblastoid cell lines.

\section{References}

1 Kaufmann WK, Filatov L, Oglesbee SE, et al. Radiation clastogenesis and cell cycle checkpoint function as functional markers of breast cancer risk. Carcinogenesis 2006, Jun 15 [E-pub ahead of print].

2 Raab-Traub N, Flynn K. The structure of the termini of the Epstein-Barr virus as a marker of clonal cellular proliferation. Cell 1986;47:883-889.

3 Gulley ML, Eagan PA, Quintanilla-Martinez L, et al. Epstein-Barr virus DNA is abundant and monoclonal in the Reed-Sternberg cells of Hodgkin's disease: association with mixed cellularity subtype and Hispanic American ethnicity. Blood 1994;83: 1595-1602.

4 Gulley ML, Raphael M, Lutz CT, et al. Epstein-Barr virus integration in human lymphomas and lymphoid cell lines. Cancer 1992;70:185-191.

5 Gulley ML, Pulitzer DR, Eagan PA, et al. Epstein-Barr virus infection is an early event in gastric carcinogenesis and is independent of bcl-2 expression and p53 accumulation. Hum Pathol 1996;27:20-27.

6 Chadburn A, Cesarman E, Knowles DM. Molecular pathology of posttransplantation lymphoproliferative disorders. Semin Diagn Pathol 1997;14:15-26.

7 Locker J, Nalesnik M. Molecular genetic analysis of lymphoid tumors arising after organ transplantation. Am J Pathol 1989;135:977-987.

8 Segal GH, Jorgensen T, Masih AS, et al. Optimal primer selection for clonality assessment by polymerase chain reaction analysis: I. Low grade B-cell 
lymphoproliferative disorders of nonfollicular center cell type. Hum Pathol 1994;25:1269-1275.

9 Greiner TC, Rubocki RJ. Effectiveness of capillary electrophoresis using fluorescent-labeled primers in detecting T-cell receptor gamma gene rearrangements. J Mol Diagn 2002;4:137-143.
10 Fan H, Gulley ML. Molecular methods for detecting Epstein-Barr virus. In: Killeen A (ed). Molecular Pathology Protocols. Humana Press: Totowa, NJ, 2001.

11 Moody CA, Scott RS, Su T, et al. Length of EpsteinBarr virus termini as a determinant of epithelial cell clonal emergence. J Virol 2003;77:8555-8561. 